\title{
PROCEDIMENTOS INVESTIGATIVOS DO ENCARREGADO DO INQUÉRITO POLICIAL MILITAR À LUZ DA CONSTITUIÇÃO BRASILEIRA
}

\section{ARTIGO DE REVISÃO}

PANTOJA, Falckner Ferreira ${ }^{1}$

MOREIRA, Sirley Santana ${ }^{2}$

PANTOJA, Falckner Ferreira. MOREIRA, Sirley Santana. Procedimentos investigativos do encarregado do Inquérito Policial Militar à luz da Constituição Brasileira. Revista Científica Multidisciplinar Núcleo do Conhecimento. Ano 04, Ed. 12, Vol. 02, pp. 14-30. Dezembro de 2019. ISSN: 2448-0959, Link de acesso: https://www.nucleodoconhecimento.com.br/lei/procedimentos-investigativos

\section{RESUMO}

Este trabalho tem a pretensão de demonstrar que os Procedimentos Investigativos do Oficial encarregado do Inquérito Policial Militar devem ser à luz da Constituição

1 Mestre em Ciências da Educação pela Universidad Privada del Guairá, Especialização em Auditoria, Perícia e Gestão Ambiental, Docência do Ensino Superior ambas pelo Centro Universitário Estácio da Amazônia, Especialização em Direito Militar pela Faculdade Venda Nova do Imigrante - FAVENI, Licenciatura em Geografia pelas Faculdades Integradas de Ariquemes, Bacharel em Direito pela Faculdade Atual da Amazônia, Bacharel em Teologia pela Faculdade Roraimense de Ensino Superior - FARES e Tecnólogo em Gestão Ambiente pelo Centro Universitário Estácio da Amazônia.

${ }^{2}$ Mestrado Em Ciências Da Educação. Especialização Em Saúde Pública E Vigilância Sanitária. Especialização Em Docência No Ensino Superior. Especialização Em Psicopedagogia E Inclusão. Graduação Em Serviço Social. Graduação Em Pedagogia. 
Brasileira. Que se assim não o for, infringirá a maior norma do nosso país, que prima pelos direitos e garantias do cidadão. Abordaremos a visão do policial militar na condição de acusado, as consequências negativas que ele poderá sofrer se for indiciado indevidamente, bem como a responsabilidade ao encarregado prevista na Lei de Abuso de Autoridade $n^{\circ} 4.898 / 65$. Buscamos apresentar os artigos do Código de Processo Penal Militar, Decreto-Lei no $1.002 / 69$ relacionados à prisão e à incomunicabilidade do preso, que não foram recepcionados pela Constituição Federal de 1988. Veremos que, o encarregado tem a discricionariedade para melhor conduzir as investigações, desde que observe os preceitos Constitucionais relacionados à busca domiciliar, à prisão e ao interrogatório do indiciado, bem como a presença de seu advogado no interrogatório, além de seu acesso aos autos já produzidos durante o inquérito de acordo com o Estatuto da Advocacia do Brasil, Lei n 8.906/94. Esta obra esclarece que pelo fato de o Inquérito Policial Militar ser um procedimento inquisitório, os vícios não comprometem a futura ação penal, não concedendo ao encarregado o direito de presidi-lo de qualquer maneira, é necessário fazê-lo à luz da Constituição Brasileira.

Palavras-chave: Inquérito, policial, militar, encarregado, indiciado.

\section{INTRODUÇÃO}

Os procedimentos investigativos do encarregado do Inquérito Policial Militar - IPM à luz da Constituição Federal - CF de 1988, tem como o intuito de respaldar o oficial da Polícia Militar de Roraima - PMRR, na tomada dos procedimentos corretos em relação às investigações, proporcionando ao(s) investigado(s) os totais direitos e garantias constitucionais expressos no art. 5º, CF/88.

Analisaremos a recepcionalidade da Constituição Federal de 1988 acerca do Código de Processo Penal Militar - CPPM, Decreto-Lei no 1.002/69, no que se refere às atribuições do encarregado durante as investigações, seus procedimentos adotados nas diligências, na busca domiciliar, à prisão e no interrogatório do indiciado dentro dos aspetos legais. 
A atuação do encarregado do IPM deve ser baseada dentro dos limites da lei, observando detalhadamente os princípios constitucionais inerentes ao indiciado, sob o prisma do art. $125, \S 4^{\circ}$, da $\mathrm{CF} / 88$, quando da prática do fato que, nos termos legais, configure crime militar praticado por integrantes das policias militares e corpos de bombeiros militares estaduais. (BISCAIA, 2006).

A função do encarregado será meramente investigar o possível crime militar, não somente baseado no CPPM, mas, principalmente, à luz da Constituição para subsidiar sua atuação nas investigações, como por exemplo, a sequência nas oitivas com ou sem a presença do advogado, as acareações, o prazo para sua conclusão e, principalmente, a legalidade da prisão do investigado e a sua incomunicabilidade.

Após a prática da infração penal militar, caberá ao encarregado do IPM desenvolver intensa atividade na busca de colher informações sobre a materialidade do fato e de sua autoria, conforme art. 9o do CPPM, e com a finalidade de fornecer ao Ministério Público Estadual - MPE, titular da ação penal, os elementos necessários ao oferecimento da denúncia. "A ação penal é pública e somente pode ser movida por denúncia do Ministério Público [...]”, (art. 29 CPPM). (ASSIS, 2006).

\section{DA JUSTIÇA MILITAR}

\subsection{HISTÓRICO DA JUSTIÇA MILITAR NO BRASIL}

Com a vinda da Família Real Portuguesa em 1808 para o Brasil, segundo escreveu Oliveira (2012:1-2)[3], o país deixou de ser Colônia para ganhar status de Reino Unido a Portugal. Com a instalação da nova Administração Portuguesa no país, precisamente no Estado do Rio de Janeiro, sob a regência do Príncipe D. João VI, foram criadas várias instituições públicas, entre as quais a Justiça Militar.

Com a criação dos ministérios, foi criado o Conselho Supremo Militar e de Justiça CSMJ, que, posteriormente, estendeu-se à Justiça Militar Brasileira, mediante o Alvará de $1^{\circ}$ de abril de 1808 , com força de lei, assinado pelo próprio Príncipe Regente D. 
João VI. Esse tribunal é, portanto, o mais antigo Tribunal Superior do País, seu bicentenário foi realizado no ano de 2008. (OLIVEIRA, 2008).

Por meio da Constituição de 1891, o CSMJ passou a intitular-se Supremo Tribunal Militar - STM, sua organização e atribuições ficaram definidas pela Lei ํㅡㄴ 149, de 18 de julho/1893. Em 1934, o STM passou a integrar o Poder Judiciário, pela Constituição daquele ano que por sua vez cria a Justiça Militar da União - JMU. Somente em 1946 com a nova Constituição. O autor detalha bem esse histórico, que, em tese, é importantíssimo para se conhecer a história da Justiça Militar no Brasil, bem como a evolução ao longo do tempo. Os órgãos que compõem a Justiça Militar estão elencados na Constituição Brasileira, em seu art. 122[4]. (OLIVEIRA, 2012).

Portanto, com esse entendimento, pode-se concluir que a Justiça Militar tem seu papel importante, que sua abrangência não está tão-somente na atividade policial militar, mas alcança também o cidadão, mesmo que indiretamente, porque se tornam vítimas de atos lesivos aos seus direitos e garantias constitucionais, praticados por policiais militares no exercício da função.

\subsection{COMPETÊNCIA DA JUSTIÇA MILITAR}

É importante, em primeiro lugar, observar que existem diferenças de finalidade entre a Justiça Militar da União e a Justiça Militar dos Estados. O artigo 124 da Constituição Federal de 1988 determina que à justiça militar compete processar e julgar os crimes militares definidos em lei.

Entretanto, os $\S 3^{\circ}, 4^{\circ}$ e $5^{\circ}$, do seu art. 125 , referem-se à Justiça Militar Estadual, de acordo com a Emenda Constitucional n 45 de 08 de dezembro de 2004[5]. (BRASIL, 2004).

A competência da Justiça Militar da União está bem expressa no art. 124, tal competência é abrangente, pois qualquer agente civil ou militar poderá ser julgado por crime militar. O que não ocorre com a competência da JME, que por sua vez é mais restrita, apenas cabendo-Ihe processar e julgar os militares estaduais. 
O $\S 3^{\circ}$ do art. 125 define os Tribunais competentes de segunda instância, em relação à Justiça Militar da União é o STM, como já foi explicado. Os únicos Estados que possuem seus Tribunais Militares Estaduais - TME, são Minais Gerais, Rio Grande do Sul e São Paulo, por terem seus efetivos superiores a vinte mil integrantes, no restante da Federação a competência é do Tribunal de Justiça. (OLIVEIRA, 2012).

Já a competência para o julgamento, em primeira instância, é dos juízes de direito do juízo militar, a quem compete ainda processar e julgar, singularmente, os crimes militares praticados contra civis.

A Lei Complementar $n^{\circ}$ 02/93, que institui o Código de Organização Judiciária do Estado de Roraima, no art. 45, além do Juiz de Direito, os Conselhos de Justiça têm as categorias de Conselho Especial de Justiça, para processar e julgar os oficiais da ativa, exceto o Comandante-Geral e o Conselho Permanente de Justiça para processar e julgar os praças da ativa.

No capítulo seguinte, trataremos sobre o IPM e suas características, bem como os procedimentos do encarregado acerca das investigações.

\subsection{AUTORIDADE JUDICIÁRIA MILITAR: CONCEITOS}

Para definir esse Instituto, é preciso interpretar o art. $5^{\circ}$ da lei 4.898/65. "Considerase autoridade, para os efeitos desta Lei, quem exerce cargo, emprego ou função pública, de natureza civil, ou militar, ainda que transitoriamente e sem remuneração". Portanto, é uma definição abrangente, mas demonstra que toda autoridade deriva de lei.

A autoridade de que trata 0 art. $4^{\circ}$ do Código de Processo Penal - CPP[6] é exclusiva do delegado de polícia que Ihe compete instaurar Inquérito Policial - IP e outros atos inerentes à Polícia Judiciária Civil - PJC, portanto, não deve ser confundido com a autoridade policial militar. A esse respeito Oliveira (2008: 12) explica que, todo Policial Militar não deixa de ser autoridade, pois os mesmos exercem atribuições próprias de polícia na preservação da ordem pública. 
Quanto ao delegado de polícia, este é autoridade policial no exercício das atividades de Polícia Judiciária. Esse status na Polícia Civil é dado somente aos delegados, uma vez que os agentes são definidos como agentes da autoridade, o que não ocorre com o Policial Militar, pois este é a própria autoridade.

\subsubsection{POLÍCIA JUDICIÁRIA MILITAR}

Enquanto a polícia administrativa tem a missão de fazer o policiamento ostensivo preventivo, a Polícia Judiciária, repressivamente, tem a incumbência de investigar. A Carta Magna define duas instituições de Polícia Judiciária e suas competências, conforme art. 144.

Assim sendo, tanto a Polícia Federal, quanto a Polícia Civil são órgãos competentes para a finalidade de apuração das infrações penais.

Com as instituições militares, o que acontece é a designação mediante delegação de autoridades militares (oficiais encarregados) competentes para esse fim. É o caso do encarregado do Inquérito Policial Militar, pois não compete ao delegado de Polícia Civil a apuração dos crimes militares.

\subsubsection{AUTORIDADE DE POLÍCIA JUDICIÁRIA MILITAR}

A Autoridade de Polícia Judiciária Militar é aquela que desenvolve todos os atos referentes a essa atividade, para tanto, é necessário ter a competência legal, isso quer dizer que nem todos os Policiais Militares podem exercer essa atividade, mas somente aqueles que o CPPM define em seu art. $7^{\circ}$. (BRASIL, 1969).

Dessa forma, em concordância com este entendimento, por se tratar de uma nova realidade, a PJM deve ser exercida em sua plenitude pelas corporações estaduais, contudo, deve ser observado o que trata as Leis atuais, inerentes a este assunto e indispensável à luz da Constituição Brasileira. 


\subsubsection{COMPETÊNCIA DA POLÍCIA JUDICIÁRIA MILITAR}

Como regra geral, a competência da PJM é apurar os crimes militares e seus autores. Essas competências estão expressas no art. $8^{\circ}$ do CPPM.

Várias são as competências da PJM, tanto para repassar informações, cumprir determinações, como expor solicitações junto aos órgãos competentes para subsidiar as investigações do IPM, é o caso, por exemplo, da solicitação do exame de corpo de delito junto à repartição técnica, bem como a perícia em arma de fogo. Mas, nem tudo o que está disposto no referido artigo é aceito pela doutrina.

\section{DO INQUÉRITO POLICIAL MILITAR}

\subsection{NATUREZA JURÍDICA}

O Inquérito Policial Militar é uma peça de informação, mas tem a natureza jurídica de Ato Administrativo e, como tal, deve obedecer aos princípios da legalidade, impessoalidade, moralidade, publicidade e eficiência previstos na Constituição Brasileira de 1988.

\subsection{CARACTERÍSTICAS DO IPM}

O Inquérito Policial Militar apresenta suas características próprias, as quais serão abordadas, para melhor entendimento, uma a uma, a cada tópico. Tais características formam a essência do IPM.

\subsubsection{OFICIALIDADE}

É o Estado que tem a obrigação de criar os órgãos oficiais responsáveis para apuração dos delitos, as investigações preliminares, nos crimes militares. Deverão ser feitas pela Polícia Judiciária Militar, assim definida nos arts. $7^{\circ}$ e $8^{\circ}$ do CPPM que tratam das autoridades que a compõe e sua competência, respectivamente. (BRASIL, 2008). 
Portanto, o Oficial Policial Militar, ora designado, tem a incumbência de apurar as infrações penais militares no âmbito da Polícia Militar, seja IPM ou outro procedimento administrativo, atuará de forma representativa do próprio órgão estatal.

\subsubsection{OFICIOSIDADE}

No tocante à oficiosidade ou obrigatoriedade, podemos citar o que está elencado nas alíneas "a" e "f" do art. 10 do CPPM. O qual estabelece que o IPM seja iniciado mediante portaria: a) de ofício, pela autoridade militar em cujo âmbito de jurisdição ou comando haja ocorrido a infração penal, atendida a hierarquia do infrator; b) quando, de sindicância feita em âmbito de jurisdição militar, resulte indício da existência de infração penal militar. (ROSA, 2000).

De ofício, a autoridade de PJM, no âmbito de sua jurisdição ou comando, que constata a ocorrência de infração penal militar, independente da provocação do juiz, do MP, da vítima ou de qualquer pessoa tem o dever jurídico de instaurar o IPM ou delegar ao oficial competente, pois o encarregado deve ser de posto superior ao do indiciado. As infrações penais militares, via de regra, são de ação penal pública, de acordo com o art. 29 do CPPM[7]. (SARAIVA, 1999).

Dentro do mesmo posto não há que se falar em instauração de IPM, mesmo o oficial sendo mais antigo que o infrator, se isso ocorrer o fato deverá ser comunicado a autoridade superior competente conforme $\S 1^{\circ}$, do art. 10 do CPPM[8]. Mas, caso não seja possível designar um oficial de posto superior poderá ser designado um oficial do mesmo posto, desde que mais antigo que o indiciado. Esta previsão está no $\S 3^{\circ}$ do art. $7^{\circ}$ do CPPM[9].

$\mathrm{Na}$ PMRR existe a figura do Oficial Coordenador, que coordena via Companhia Independente de Operações de Segurança - CIOPs, as ações das patrulhas empregadas no policiamento ostensivo da Capital, as guardas dos presídios, quartéis e alguns órgãos públicos. Existe também a competência do Oficial de Operações, que diretamente atua na fiscalização do policiamento junto às patrulhas, no local das ocorrências. (RORAIMA, 1993). 
Assim, tanto o Oficial Coordenador quanto o de Operações, têm a autonomia de designar qualquer patrulha ou efetivo ao local da infração e determinar que sejam tomadas as medidas preliminares, no intuito de evitar que se altere o estado das coisas, isto é fato. Esses procedimentos não devem fugir das normas vigentes, e toda observância será relevante à dignidade dos envolvidos na infração militar à luz constitucional.

\subsubsection{INDISPONIBILIDADE}

Assim como no inquérito comum, em que o delegado de polícia não tem competência para arquivá-lo, a autoridade de Polícia Judiciária Militar não poderá arquivar os autos do IPM. Esta previsão está determinada no art. 24 do CPPM, a autoridade militar não poderá mandar arquivar autos de inquérito, embora conclusivo da inexistência de crime ou de inimputabilidade do indiciado. (SARAIVA, 1999).

Assim sendo, se for concluído no relatório final que não houve crime militar, ou que se trata de comum, ou foi praticado no amparo de uma excludente de criminalidade ou de culpabilidade, de forma alguma o encarregado ou a autoridade delegante poderá mandar arquivá-lo.

Em qualquer situação, uma vez instaurado e concluso, a autoridade militar determinará a remessa dos autos do IPM à Justiça Militar, a esta Ihe compete o envio à autoridade de Polícia Civil ou Justiça Comum, nos casos de crimes dolosos contra a vida de civil, de acordo com o $\S 2^{\circ}$ do art. 82 do CPPM[10], ou determinar seu arquivamento. (BRASIL, 1992).

A competência para determinar o arquivamento do IPM pertence ao juiz de direito, se achar conveniente que assim seja feito, ou por meio de requerimento[11] do Ministério Público. A atribuição do encarregado é meramente apurar a suposta infração penal militar, diante de diligências, e buscando pautar suas ações à luz da Constituição Federal. 


\subsubsection{PROCEDIMENTO ESCRITO}

É obvio que o IPM, por ser um procedimento de suma importância à propositura da ação penal, deve ser levado a termo e assinado pelo encarregado e seu escrivão, assim como, todos os envolvidos na investigação. Os atos praticados pelo encarregado durante as investigações não podem ser verbais. Observe o que segue no art. 21 do CPPM: "Todas as peças do inquérito serão, por ordem cronológica, reunidas num só processado e datilografadas, em espaço dois, com as folhas numeradas e rubricadas, pelo escrivão". (Grifo nosso).

"Parágrafo único. De cada documento junto, a que precederá despacho do encarregado do inquérito, o escrivão lavrará o respectivo termo, mencionando a data".

Com a informatização, os documentos públicos deixaram de ser datilografados e passaram a ser digitalizados. Todos os atos do encarregado devem ser juntados ao IPM de forma cronológica, o escrivão terá a responsabilidade de organizar as folhas, numerá-las, datá-las e rubricá-las. Essa organização facilitará ao encarregado o manuseio nos autos, bem como ao promotor de justiça e ao próprio juiz. (SOUZA JR, 2009).

\subsubsection{AUSÊNCIA DE RITO PRÓPRIO}

Muito embora o CPPM em seu art. 13, determina algumas medidas a serem tomadas pelo encarregado, não significando que há um rito a seguir no curso do Inquérito Policial Militar. Dessa forma, não necessariamente, deve-se seguir a sequência expressa por este artigo, ou seja, o encarregado poderá decidir sobre a maneira conveniente de atuar nas investigações, até porque os vícios formais no IPM são irrelevantes, o que não impede a propositura da ação penal.

O encarregado tem a discricionariedade na condução das investigações. Porém, não a tem em relação ao Auto de Prisão em Flagrante, que deve ser lavrado conforme ditado na lei, do contrário à prisão em flagrante poderá ser relaxada. E por conta disso, 
a autoridade judiciária correrá o risco de responder judicialmente por crime contra o dever funcional, conforme previsão no Código Penal Militar. (SIRINO, 2001).

\subsubsection{DISPENSABILIDADE}

Em tese, o IPM é obrigatório, como foi abordado anteriormente. Porém, o art. 28 do CPPM dispensa a sua instauração, conforme o Art. 28.

Como se pode observar, o IPM não é essencial ao oferecimento da denúncia, se os fatos já forem esclarecidos por meio de outra provas ou documentos, como a sindicância, a exemplo, que tornem claro a materialidade do crime militar, não há motivo de sua instauração. E ainda nos crimes contra a honra ou previstos nos arts. 341[12] e 349[13] do Código Penal Militar - CPM.

Da mesma forma, o art. 27 do CPPM, em relação ao auto de flagrante delito, no qual se estabelece que se no próprio auto houver esclarecimento da materialidade e autoria do crime, ele por si só constituirá o IPM, e o encarregado deve remetê-lo imediatamente ao juiz competente. Porém, nos crimes que deixarem vestígios, será indispensável o exame de corpo de delito e este deverá acompanhar o auto de prisão. Sendo assim, se no próprio auto de prisão em flagrante delito for constatado materialidade do fato e sua autoria, não se fará necessária a instauração do IPM. (OLIVEIRA, 2008).

\section{DIREITOS DO INDICIADO NO IPM}

Durante a fase do inquérito, ainda que não existam acusações formalizadas, mas no entendimento deste pesquisador, ao indiciado devem ser garantidos todos os direitos que também pertencem aos acusados de forma geral. O indiciado deve ser tratado, em quaisquer circunstâncias, com respeito à dignidade da pessoa humana e os direitos e garantias fundamentais previstos na Constituição e Tratados Internacionais, dos quais, o Brasil é signatário, porém o indiciado poderá exercer suas funções normalmente na unidade em que trabalha, o fato de estar sendo investigado por 
suposto crime militar não o obsta de continuar na atividade, desde que, não existam fortes restrições que recomendem o contrário. (MEIRELES, 1994).

\subsection{PARTICIPAÇÃO DO ADVOGADO DO INDICIADO}

O art. 16[14] do CPPM considera o IPM como sendo um procedimento sigiloso, mas com o advento constitucional (LXIII, art. $5^{\circ}$ ), como já foi abordado, e do Estatuto da Advocacia do Brasil (Lei n 8.906, de 04 de julho de 1994), o indiciado passa a ter o direito de ser acompanhado pelo seu defensor, e isso vale tanto para o interrogatório quanto para as outras fases do IPM. Observe o que estabelece os incisos III, XIII e XIV, do art. $7^{\circ}$, do referido Estatuto. (MIRABETE, 1997).

Por esse embasamento legal, não há que se discutir hoje a participação do advogado do indiciado nos autos do IPM. O encarregado não tem a discricionariedade de permitir ou não a participação do defensor, mas de acatar, pois se trata de uma norma legal.

Em colaboração a essas afirmações, Paulo Tadeu Rosa[15], acrescenta que o IPM não pode e não deve ser um procedimento administrativo onde seja vedado ao advogado acompanhá-lo, o sigilo disposto no CPPM passou a ser relativo, pois deve estar sob o crivo Constitucional e ao Estatuto da advocacia. (ROSA, 2000).

É importante ressaltar que o direito de tomar conhecimento dos autos pertence ao Juiz, Promotor de Justiça e ao advogado do indiciado, somente. As outras pessoas arroladas no IPM não têm esse direito.

Durante o interrogatório do indiciado, estando este preso ou não, o advogado terá o direito de acompanhá-lo normalmente, uma vez que seu cliente não poderá mais ficar incomunicável, desde que não interfira na presidência do IPM. Contudo, não permitirá que os princípios constitucionais inerentes a ele e ao indiciado sejam violados. (BRASIL, 1992).

Dessa forma, não torna ato ilegal do encarregado o fato de aceitar que o indiciado seja interrogado sem seu defensor, pois não se trata de uma determinação da 
Constituição, mas um direito que lhe é assegurado, cabendo ao indiciado avocá-lo ou não.

Nem por isso, a autoridade militar que estiver presidindo o IPM poderá durante as investigações, deixar de cumprir os princípios constitucionais que são assegurados a todos os brasileiros e estrangeiros residentes no Brasil, de acordo com o art. 5.․ caput, e seus incisos. (ROSA, 2000).

\subsection{QUANDO DA PRISÃO DO INDICIADO. ESTA PREVISÃO SE ENCONTRA NO ART. 18 DO CPPM}

Dessa forma, com exceção de flagrante delito, que poderá também ser por insubmissão e deserção, ambos previstos no art. 243[16], do CPPM, pois se trata de crimes próprios, a prisão do indiciado só ocorrerá por ordem judicial, e esta deve ser fundamentada em fortes indícios de crime militar, como já vimos.

Sendo assim, a representação da prisão preventiva pelo encarregado deverá ser fundamentada diante das circunstâncias que cercam o delito militar, ou do que ela vai representar para o cumprimento da norma jurídica, e não simplesmente baseada em suposições.

\subsection{QUANDO DA INCOMUNICABILIDADE DO INDICIADO}

$\mathrm{O}$ art. 17 do CPPM normatiza que o encarregado do inquérito poderá manter incomunicável o indiciado, que estiver legalmente preso, por três dias no máximo. Vamos considerar o indiciado que está legalmente preso, ou por flagrante delito ou por ordem da autoridade judiciária, como vimos em outro tópico. Levando em conta que a Constituição Federal de 1988 é a "Constituição Cidadã", que preza pelos direitos e garantias de qualquer brasileiro e a dignidade da pessoa humana, torna-se, portanto, revogado a execução do art. 17. A referida Constituição afastou a possibilidade do preso ficar incomunicável. (ASSIS, 2006). 
Esse fato é bastante coerente, se no estado de defesa, em que alguns direitos serão restringidos em vista à segurança do país, estará vedada a incomunicabilidade, no estado de normalidade não será diferente. Se o encarregado vedar a comunicabilidade do indiciado, além de ferir o preceito constitucional, poderá responder por abuso de autoridade.

Sendo assim, por base do texto constitucional, que não recepcionou o art. 17 do CPPM, este passou a estar tacitamente revogado. Para Rosa (2000) o cidadão, civil ou militar, não mais poderá ficar impedido de se comunicar reservadamente, ainda que seja decretada a prisão preventiva do militar, este não estará cerceado de seus direitos constitucionais.

O encarregado do IPM ao tomar qualquer medida em relação ao indiciado, deverá não somente, ter embasamento legal em relação ao CPPM, mas à luz da Constituição Federal.

\subsection{QUANDO DO INTERROGATÓRIO DO INDICIADO}

Não há no CPPM um procedimento definido para ouvir o indiciado, no entanto se aplicam os mesmos procedimentos adotados para interrogar o acusado.

Assim como, na fase processual o interrogatório do acusado deve ser feito, obrigatoriamente, pelo juiz de direto, o indiciado deve ser ouvido, obrigatoriamente pelo encarregado, ou seja, para esse procedimento não cabe carta precatória.

O termo que se aplica ao indiciado para registrar suas declarações é o Termo de Perguntas ao Indiciado. Note que as perguntas são diretas e concisas, o objetivo é colher as provas suficientes para a conclusão dos autos. (SIRINO, 2001).

O indiciado, se quiser, poderá até mentir nas suas respostas e na sua versão sobre o fato. Mesmo que sua mentira seja comprovada durante as investigações do IPM, ele não poderá ser punido disciplinarmente por isso. 
Sendo assim, cabe ao encarregado do IPM, independente da versão do indiciado, produzir as provas necessárias à autoria e materialidade do crime militar, da mesma forma que as provas produzidas poderão apontar sua inocência.

\subsection{O CONTRADITÓRIO E AMPLA DEFESA NO IPM}

Este requisito está evidenciado no art. 5ํ, LV, da CF/88 - aos litigantes, em processo judicial ou administrativo, e aos acusados em geral são assegurados o contraditório e a ampla defesa, com os meios e recursos a ela inerentes. (Grifo nosso).

Porém, existe uma exceção que foge a esta regra, ou seja, inquérito que é admitido o contraditório e ampla defesa, trata-se do inquérito instaurado pela Polícia Federal, a pedido do Ministro da Justiça, visando à expulsão de estrangeiro (DECRETO № 86.715/81)[17].

Portanto, mesmo tendo o Inquérito Policial Militar caráter inquisitivo, onde em regra, não são admitidos os direitos da ampla defesa e do contraditório, entende-se que os procedimentos investigativos de seu encarregado, jamais deverão atentar contra a dignidade da pessoa humana do indiciado e devem ser garantidos a ele, todos os direitos previstos na Constituição Brasileira de 1988 e nos Tratados Internacionais que o Brasil é signatário.

\section{CONSIDERAÇÕES FINAIS}

O Inquérito Policial Militar é um procedimento inquisitivo, que isenta os recursos constitucionais da ampla defesa e do contraditório, entretanto, isso não quer dizer que o encarregado no período das investigações possa cometer impunemente excesso de autoridade e atentados à dignidade da pessoa humana, impedindo assim, o cometimento do crime de abuso de autoridade.

Com isso, os atos investigativos do encarregado do inquérito podem e devem ser de todos aplicáveis a legalidade, principalmente ao iniciar de ofício o inquérito, deve o encarregado, estar convicto, que não basta apenas presunção, mas a busca de significativas provas da materialidade e indícios satisfatórios de autoria, para tornar- 
se legítima a investigação, impedindo assim, constrangimentos ilegais e gastos supérfluos à administração Policial Militar.

Destarte, sugere-se que o responsável do Inquérito Policial Militar, não adote por base para suas investigações somente as Leis Penal e Processual Militar, mas que tome como fundamento a Constituição Federal Brasileira, pois é indispensável observar que esta não recepcionou alguns artigos da lei castrense, como exemplo, a incomunicabilidade do preso e a prisão independente de flagrante delito. Sendo assim, evitará processo judicial contra si.

\section{REFERÊNCIAS}

ASSIS, Jorge César de. Código de processo penal militar anotado. 2. ed. ver. e atual. Curitiba: Juruá, 2006, p. 37-38.

BISCAIA, Ederson José. O Inquérito Policial Militar no Âmbito das Polícias Militares Estaduais. Guarapuava, 2006. 89 f. Faculdades Campo Real - Unicampo. Monografia.

BRASIL. Abuso de Autoridade, Lei n 4.898, 1965.

. Código de Processo Penal Militar. Decreto Lei n 1.002. 1969.

. Código de Processo Penal. Decreto Lei no 3.689. 1941.

. Constituição. Brasília: Senado federal, 1988.

Decreto $n=86.715$ de dez de dezembro de 1981. Regulamenta a Lei $n$ 6.815, de 19 de agosto de 1980, que define a situação jurídica do estrangeiro no Brasil;

. Emenda Constitucional nº 45 De 08/12/2004 - DOU 31/12/2004.

. Promulga a Convenção Americana sobre Direitos Humanos (Pacto de São José da Costa Rica), de 22 de novembro de 1969. Decreto n 678, de 6 de novembro de 1992. 
. SUPREMO TRIBUNAL FEDERAL. Indiciado. Interrogatório. Presença de defensor. $1^{\circ}$ Turma - Rel. Min. Celso de Mello - DJU 14.08.1992.

. SUPREMO TRIBUNAL FEDERAL. Inquérito Policial e Direito de Vista. HC 94.378/RS - Rel. Min. Ricardo.

. SUPREMO TRIBUNAL FEDERAL. Súmula Vinculante $\mathbf{n}^{\circ} \mathbf{1 4}$, aprovada em 02 de fevereiro de 2009.

MEIRELLES, Hely Lopes. Direito administrativo brasileiro. 19. ed. atual. por Eurico de Andrade Azevedo, Délcio Balestero Aleixo e José Emmanuel Burle Filho. São Paulo: Malheiros, 1994.

MIRABETE, Júlio Fabbrine. Código de Processo Penal interpretado. 5. Ed. São Paulo: atlas 1997.

OLIVEIRA, Manoel, Élio de. Manual de Polícia Judiciária Militar, $2^{\circ}$ ed., Curitiba: OPTA, 2008.

OLIVEIRA, Rodrigo Montenegro de. Justiça Militar no Brasil. Jus Navigandi, Teresina, ano 17, n. 3185, 2012. Disponível em: $<$ http://jus.com.br/revista/texto/21339>. Acesso em: 8 janeiro de 2018.

RORAIMA. Lei Complementar no 002 de 22 de setembro de 1993. Institui o Código de Organização Judiciária do Estado de Roraima.

. Constituição do Estado. Palácio Antônio Martins, 31 de dezembro de 1991.

ROSA, Paulo Tadeu Rodrigues. Princípios Constitucionais e Inquérito Policial Militar. Jus Navigandi, Terezina, ano 5, n. 45, 1set. 2000. Disponível em: <http://jus.com.br/revista/texto/1584>. Acesso em: 28 dez. 2017.

Justiça Militar e o Estado Democrático de Direito. Jus Navigandi, Teresina, ano 10, n. 813, 24 set. 2005. Disponível em: $<$ http://jus.com.br/revista/texto/7326>. Acesso em: 17 dezembro de 2018. 
SARAIVA, Alexandre José de Barros Leal. Inquérito Policial e Auto de Prisão em Flagrante nos Crimes Militares. São Paulo: Atlas, 1999.

SIRINO, Sérgio Inácio; GIOSTRI, Hildegard Taggesell. Inquérito Policial. Coleção Perguntas e resposta. Curitiba: Juruá, 2001.

SOUZA JUNIOR, Edgard Antônio de. Atividade jurídica exercida por oficiais das polícias militares. Jus Navigandi, Teresina, ano 14, n. 2285, 3 out. 2009. Disponível em: <http://jus.com.br/revista/texto/13620>. Acesso em: 17 dezembro de 2018.

\section{APÊNDICE - REFERÊNCIAS DE NOTA DE RODAPÉ}

3. Rodrigo Montenegro de Oliveira é Advogado da União, com exercício funcional na Consultoria Jurídica do Ministério da Defesa da República Federativa do Brasil.

4. Art. 122. São órgãos da Justiça Militar:

I - o Superior Tribunal Militar;

II - os Tribunais e Juízes Militares instituídos por lei.

\section{EMENDA CONSTITUCIONAL № 45 DE 08/12/2004 - DOU 31/12/2004: Altera} dispositivos dos arts. 5, 36, 52, 92, 93, 95, 98, 99, 102, 103, 104, 105, 107, 109, 111, 112, 114, 115, 125, 126, 127, 128, 129, 134 e 168 da Constituição Federal, [...].

6. Art. 4ํㅗ A polícia judiciária será exercida pelas autoridades policiais no território de suas respectivas circunscrições e terá por fim a apuração das infrações penais e da sua autoria.

7. Art. 29. A ação penal é pública e somente pode ser promovida por denúncia do Ministério Público Militar.

8. $\S 1^{\circ}$ Tendo o infrator posto superior ou igual ao do comandante, diretor ou chefe de órgão ou serviço, em cujo âmbito de jurisdição militar haja ocorrido a infração penal, 
será feita a comunicação do fato à autoridade superior competente, para que esta torne efetiva a delegação, nos termos do $\S 2^{\circ}$ do art. $7^{\circ}$.

9. $§ 3^{0}$ Não sendo possível a designação de oficial de posto superior ao do indiciado, poderá ser feita a de oficial do mesmo posto, desde que mais antigo.

10. Art. 82. O foro militar é especial, exceto nos crimes dolosos contra a vida praticados contra civil; a ele estão sujeitos, em tempo de paz:

$\S 2^{\circ}$ Nos crimes dolosos contra a vida, praticados contra civil, a Justiça Militar encaminhará os autos do inquérito policial militar à justiça comum.

11. CPPM: Art. 25, $\S 2^{0} \bigcirc$ Ministério Público poderá requerer o arquivamento dos autos, se entender inadequada a instauração do inquérito.

12. Art. 341 - Desacatar autoridade judiciária militar no exercício da função ou em razão dela:

13. Art. 349 - Deixar, sem justa causa, de cumprir decisão da Justiça Militar, ou retardar ou fraudar o seu cumprimento:

14. Art. 16. O inquérito é sigiloso, mas seu encarregado pode permitir que dele tome conhecimento o advogado do indiciado.

15. Paulo Tadeu Rodrigues Rosa: juiz-auditor da Justiça Militar do Estado de Minas Gerais, mestre em Direito Administrativo pela Unesp, especialista em Direito Administrativo pela Unip, é também integrante da Associação dos Diplomas da Escola Superior de Guerra (ADESG/SP), membro titular da Academia Ribeirão Pretana de Letras Jurídicas e membro correspondente da Academia Brasileira de Letras Jurídicas.

16. Art. 243. Qualquer pessoa poderá e os militares deverão prender quem for insubmisso ou desertor, ou seja encontrado em flagrante delito. (Grifo nosso) 
17. Art. 103. A instauração de inquérito para a expulsão do estrangeiro será iniciada mediante portaria.

$\S 7^{\circ}$ Cumprido o disposto nos parágrafos anteriores, ao expulsando e ao seu defensor será dada vista dos autos, em cartório, para a apresentação de defesa no prazo único de 6 (seis) dias, contados da ciência do despacho respectivo (grifo nosso).

Enviado: Setembro, 2019.

Aprovado: Dezembro, 2019. 